\title{
When Meeting Needs Becomes a Threat to Autonomy
}

JIM SUMMERS

Eellers, Lacy and Gaddis, Austin, Texas

Meeting or defining basic human needs has long been a primary concern of policy makers, social theorists, social scientists, philosophers, and a host of other professionals. Indeed, we can find Plato, in Book IX of the Republic. making distinctions between basic needs and wants. More modern theorists bulld on the distinction between basic and derived needs to erect various hierarchies of needs. These distinctions can indeed be drawn, but they are not useful for social planning or handing $1.88 u e s$ in social and political philosophy such as rights to have basic needs met. Instead, the distinction between basic and derived needs, and the hierarchies which may be built on 1 , lead to an increase in the degree of professional control over our lives. This surfaces as a lessening of autonomy considered as the capacity to exercise choice and make plans, and as a lessening of the actual freedom with wilch to choose.

My argument for this claim will be made by accomplishing the following tasks: 1) a description of three need dichotomies and the hierarchies built on them; 2) scrutiny of the way in which such distinctions and hierarchies lead to professional control resulting in a 1088 of autonomy and various liberties; 3) identification of the root cause for the inadeguacy of such distinctions; and, 4) a brief presentation of ideas toward a solution.

\section{NEED DICHOTOMIES AND HIERARCHIES}

The language of needing reflects a very deep belief in a recurring dichotomy reflected in the following contrasts between types of needs: basic/derived, vital/heteronomous, objective/subjective, biological/social, true/false (Marcuse speaks of "false consciousness" to go along with these needs'), and needs and drives/wants, preferences, interests, choices (implying a difference between brute animal needs and needs arising because of our capacity to make plans and direct our activities in accord with them). Surely we can reach agreement, one may ask, on the general fact of basic needs for air, water, food, clothing, shelter, 
and perhaps even sex? Certainly. Surely we can agree that luxuries, or something we just want, are not basic needs? Certainly. Nonetheless, the inadequacy of these distinctions will clearly emerge when we examine the conversion of these abstract terms into specific things, products, and services which would be experienced as meeting the need.

However, there is debate even at the abstract level. For some would exclude clothing and perhaps even shelter from the category of basic needs because, under certain conditions like those of South Seas islanders or Australian aborigines, neither clothes nor shelter appear necessary. Others would exclude sex since a life of celibacy is certainly possible. Someone else would appeal to some idea of normalcy and add these back in, along with companionship, energy and health care or even education and transportation. Such a state of affairs has led Norman Daniels to conclude that there is no satisfactory theory of needs. ${ }^{2}$

Behind such discussions about needs lurks an old desire to get at some sort of essential human nature, to find the necessary conditions for a distinctly human existence, at least biologically considered. Also, the decision as to what constitutes basic needs has a moral significance if "rights" claims are based on needs. If needs establish rights, nearly all agree that such needs must be objective, however they are defined." Some attempts to resolve this problem have led to the building of hierarchies on top of the dichotomy of basic vo. derived needs. Three representative examples will be examined to see the ways such distinctions work.

\section{Maslow's Eive Step Needs Hierarchy}

The best known "needs hierarchy" is that of the theoretical psychologist Abraham Maslow." In Maslow's theory there are five levels of needing, beginning with basic needs which are physiological. A drowning man wants air and at that moment, needs nothing more. Should he survive, his needs escalate to security requirements, insuring that air, food, shelter, water, and so on may be taken for granted. Beyond these basic needs we pass into social and personal needs. Since these are not usually immediate threats to survival if lost, most people use the language of wants, preferences, and interest to describe them. Maslow gives us three categories at this level. Belongingness is a need to be part of a social community, a group. Selfesteem is described as a need to be recognized, to have a sense of worth, peer approval, accomplishment. Last we find self-actualization, the need for self-fulfillment, for completeness, for being all you can be. Maslow believes that the lower needs must be met before the higher ones can be felt and that a person should 
strive to achieve at the higher levels, transcending the need to accumulate material goods. Maslow's needs hierarchy develops into a theory of human nature and a prescription for the good life. More recent philosophical writers have refined the hierarchy to handle problems about rights-claims and distributive justice.

\section{A Right to Normalcy}

David Braybrooke considers basic needs to be of two sorts." Eirst, there are course-of-life needs which everyone must have either throughout life or at certain times, like infancy, in order to function as a normal member of the species. Related to these are special needs an individual may have because he is a diabetic, an amputee, or so on, which are labeled variation needs. Both types are objective needs and carry moral primacy. - Other lieeds are for day-to-day life in the sense of needing a tool, or for long range plans such as needing an education, and are adventitious, lacking moral obligation to be met. He goes on to describe social status and social change needs, but leaves unclear where to draw the line on their degree of objectivity, on their moral primacy, on the obligation that they be met. ${ }^{7}$ His problem lies in deciding just what is normal for the human species, a problem even at the physlological level." "Normal" is largely determined by social factors. My sense of self and my normal existence may be threatened by losses that prevent earning income at a high level, such as a surgeon losing use of his hands. Does this become a variation need? Because of social changes many consider a car a necessity in Los Angeles. Is this a form of variation need? Braybrooke appears to recognize these difficulties, but does not tackle them. His theory paints him into a corner. He does not want to prescribe a proper life because he believes we should have more freedom to define it individually and locally. But his needs theory seems to commit him to it by relying on a concept of normalcy which goes beyond biological necessity.

A theory of needs as dichotomies or hierarchies does prescribe a notion of a good life. It does so through presupposing the criteria by which the distinctions are drawn. To decide something is $X$ rather than $Y$ entails a theoretical framework grounding the distinction. Examples would include the criteria for being human, as in the abortion controversy, or what constitutes membership in a species, or what are the properties of a living organism, or what constitutes being real vs. being an illusion or a mere subjective phenomenon. Making distinctions with moral overtones concerning basic or derived needs likewise requires decision-relevant criteria. The basis of these criteria must be sought in a theory of the proper or normal human life. This outcome is unavoidable because all 
conceptions of basic needs are initially couched in the language of rudimentary existence or bare survival. As we move into derived needs and up the hierarchy these needs are always described in terms of a more satisfying and meaningful life. Mccloskey, the last example of a needs hierarchy theory, boldly takes the plunge and relates his needs theory to a theory of human nature and the proper life."

\section{A Right to What is Good for Us}

McCloskey makes the normative claim that the only items which should be counted as needs arise from a consideration of human nature, especially the human potential for good, or from consideration of what is necessary for the continued existence of individuals with potential for good, such that the good can be actualized, the development not impaired or marred. 10 What we need relates to what is good for us as humans. Mccloskey, by defining human nature in terms of capacities for rationality, sentience, emotional capacity, and imagination, would disagree with Braybrooke that a society's normal expectations can determine needs. Needs for what is adverse to our good development or existence are false needs no matter how strongly they are felt or held to be "normal." Here McCloskey sounds much like Marcuse when he discusses false needs and the false consciousness which makes the experience of them seem to be vital or true.11 Like so many others. Mccloskey is committed to the view that where a true need exists, resources should be directed to its satisfaction.12 Mccloskey, like Braybrooke, is concerned that needs, due to their moral primacy, may require such attention that resources for individual interests or Braybrooke's adventitious needs, may be lacking. Mccloskey thus wishes to restrict the concept of needs. However, the distinction is not easily amenable to restriction on the conceptual level and certainly not so in the political arena. Neither "normalcy" nor the necessities for a proper life fill the bill when we seek criteria for deciding what we have rights to or how to allocate resources based on those rights.

It appears that defining human nature and the good or proper life has been successful only within fairly stable or isolated communities or societies. Most modern-day theorists emphasize development of capacities and capabilities such as rational free agency, responsibility, autonomy, liberty, and the like.i' Basic needs, whatever they are, generally are portrayed as necessary conditions for these capabilities." While this sounds reasonable enough, great care must be exercised in moving from needs to rights. 
Theories of justice usually proclaim that the formal principle of justice is that the distribution of burdens and benefits should fall equally unless there is a material, that is, a morally relevant reason, to distribute them otherwise. Developing a material principle of justice is what lets us decide whether inequalities are just and whether there is a right to having any specific inequalities redressed. Needs and merit are two favored material principles, but needs seem easiest to define because of Rawls's argument that many, if not all, of the factors resulting in merit can be traced to good or bad fortune. 15

A major advantage for professionals and politicians results from the emphasis on need as the well-spring of rights and as the basis of unequal distributions to redress needs. It gives the politician a moral base for the advocacy of programs which may be useful in getting votes. After all, who could be against meeting basic human needs? Professionals benefit because it is usually their services which are prescribed to study the extent of the need, suggest solutions and then administer or work in the programs which will meet the needs. Social planners usually move straight from the idea that having needs implies having rights to allocating specific goods and services. This occurs without considering whether it is clear how far needs go in making rights claims. "Normalcy" seems too easy to inflate and seems questionable to many in terms of whether normal is appropriate, proper, or good. As already noted, because of inflationary tendencies, use of normalcy as a criterion threatens liberty by making it appear possible to have a right to whatever we strongly want so long as our "normalcy" would be impaired without it. The other approach, basing rights on a theory of proper human nature and what is needed for it, promises to be undemocratic. To tell a person that what they need, even for their survival, is a false need owning to false consciousness sounds like the imposition of one's views on another. This is tyranny if such persons control the relocation of resources which meet needs, however defined."

As is common in philosophy, we find disagreement at the abstract level and not just when converting categories like food, clothes, and shelter into actual items such as steak or rice, furs or jeans, two-story houses or adobe huts. Whereas normalcy will do for Braybrooke and Daniels, Mccloskey and Marcuse focus on the "proper" life. In spite of disagreements about human nature, the proper life, normal human functioning, or where to draw the line between true and false needs, or objective and non-objective needs, there does seem to be some agreement between these theorists concerning the threat to liberty from inflation of rights claims. 


\section{MEETING NEEDS AND PROFESSIONAL CONTROL}

Virtually all of these students of human needs have expressed concern over how the concept of needs is inflated at the expense of liberties or resources which would go to meet desires, preferences, interests, or adventitious needs. It appears that meeting the necessary conditions for the exercise of our rationality, our liberty, and our autonomy may become such vast tasks that opportunities for the exercise of these valued human activities may become even more remote. The determination of there being an objective need leads to a rights claim. This holds true no matter what sort of theory grounds these assessments of needs: normalcy, proper human function, the proper conditions for a becoming existence, or others. At some point of escalating needs and the correlated rights claims there will be few resources left for preferences, adventitious needs, or even liberty. A powerful way to avoid confronting this issue is to assume constant economic growth and to proclaim the eventual benefits of such growth to those whose needs are not now being met. The possibility of finite resources or the impact of growing per capita consumption of material goods on those resources or the environment goes largely unconsidered in the rush for technological mastery and ever more economic growth.

\section{Professionalization of Needs}

If there are objective needs and if they carry a moral mandate to be satisfied, there should be little surprise that vast institutions and legions of professional cadres spring into being in order to do good. The ideals of liberty, autonomy, service, and the like give such institutions an official mission, justifying their existence in terms of doing good, of beneficence. But the impact of these institutions, what happens as they carry out their mission, may be far different. Indeed, it will be argued that many of the institutions set up to meet our needs have allowed professional control of those needs."

This process probably brings to mind the image of capitalists undermining indigenous and relatively selfsustaining cultures. By first tapping or exploiting them for raw materials or cheap labor, the basis of local autonomy and a locally sustained economy--use of local resources and the skilis to utilize them--is undermined in favor of a limited number of activities carried out primarily for wages. Secondly, as the income level rises, such that poverty is the inability to consume or buy rather than to produce, these areas become markets for sale of goods produced elsewhere. A previously self-sustaining economy becomes merged within the international economy and finds itself subject 
to the new vagaries of oil prices, inflation, monetary valuations, policies of creditors, and the World Bank. We call this development. The professionalization process, however, takes this further, and is found also in the industrial-developed areas.

\section{Meeting Needs Requires Consumption}

The professionalization process converts the person in need into a consumer of professionally administered and designed outputs. For a person socialized in an industrial society, having a need translates into a consideration of how to obtain the currency necessary to purchase something to satisfy the need. It is almost totally alien to conceive of meeting a need by some sort of personal or group activity. Where this still occurs, the area is considered to be underdeveloped. Needs, wants, preferences, or interests once met locally or individually are now met only by consumption of outputs over which there is increasingly little local or individual control. The industrial solution to a need for transportation is an example.

Automobiles designed to meet a need for transportation have come to dominate the society. Local resources usually cannot produce an automoblle, and frequently cannot repair it. Moreover, as speeds increase and congestion intensifies, non-mechanized means of transport are crowded off the roads by cars. As the society has reorganized to take advantage of the automobile, the distances required to go where one wants have increased. Non-mechanized movement has become mostly recreation. Few people walk, run, or bicycle to get anywhere, at least in order to really do anything like shop, work, or even visit. Freeways often split cohesive neighborhoods as effectively as rivers, rendering non-mechanized movement virtually impossible and leaving even vehicular movement inconvenient.

Paradoxically, the freedon automobiles give is purchased at the cost of dependence, a dependence made clear when they break. The awareness of this dependence and the lack of options became generally clear for a short time during the 1974 gas shortage. A national panic nearly ensued. The cost to the world in terms of resources used to support this method of meeting a need, promises to render it a short term experiment. The point here is that we have traded in an entire social structure based on local resources and skills for one designed and administered by others less under our influence. One set of choices on how to meet needs was replaced by a different set, but a set less under our control. The precariousness of the new means of meeting needs becomes apparent only when threatened, and then the lack of local solutions becomes evident. The dependency is clearest to those who lack automobiles but are faced with meeting needs by methods which 
presuppose them. No longer can the typical member of industrial society go where he wants to get what he needs under his own power. He must rely on consuming professionally designed and administered outputs, be they automobiles, roads, or mass transit. Thus, the poverty of a ghetto dweller relative to transportation is deeper than that of a peasant in an underdeveloped area. The peasant can probably obtain what satisfies his needs, without the frustrations of mass transit and without his being reminded that he is the second-class poor because he lacks a car.

That: most people in an industrial society need a car is an example of Braybrooke's social change needs. The persons rendered poor and dependent by the social changes of industrialization are what Illich calls the modernized poor." They are poor because of social changes which require consumption of what others produce in order to meet needs. The social infrastructure has disappeared by which their own labor could directly meet their needs by using local resources and the local economy. Skills are valuable only to the extent they command a wage, not at all in terms of satisfying a need directly. Thus, a major aspect of industrialization and the professionalization process is converting producers into consumers of products largely controlled by others. The next stage in the professionalization process finds the professional capable of defining the person as having a need for that which only the professional can ascertain, provide, or determine if the need was met. Medicine exemplifies this final step in the professionalization process.

Professionalization in Medicine

Medicine is largely founded on the value of beneficence, benefitting the injured and sick. By and large, we decide if we are injured or sick, although that decision is not always left to the individual, especially in cases of mental illness. But in any case, once we consult a practitioner of the healing arts, we often lose control over our need. The professional or provider defines what our need is, what will meet the need, and often is considered the only one competent to determine if what he provided in fact met the need he originally defined. The consumer presents a pain or symptom, the physician tells him what he has, what he needs, and then is often the only one who can say if it worked. The latter situation is often true for symptoms that only show up in x-rays or lab tests. Further, like most specialized activities, a highly technical language is used among the providers, making informed consent or even the explanation of the need difficult. Yet the loss of control to professionals extends further than that. 
Physicians have a legal monopoly on the practice of medicine, extending to its very definition. This is the final step in professionalization. Thus the consumer, even if he were motivated to learn the language and become knowledgeable about therapies and medicines, would find he could not get them without the physician's orders. The inability to do anything with the knowledge you could obtain undermines any desire to get it. One result of such a legal monopoly, presumably to protect the public, is that there is no motivation to exercise one's autonomy in medical matters other than in choosing providers or signing consents. It is encouraging that reactions to this monopoly have arisen and seem to be gaining strength. This is not to say we should practice medicine on ourselves, although many afflictions can be properly diagnosed and treated without the training required to be licensed as a physician. It is to say that the entire domain of health care as a need has been taken over by professionals. Most of us have no reason to do more than be consumers. This, then, is the professionalization process: define the need, what will meet it, whether it was met, all the while holding the client responsible for compliance with the prescription. Small wonder too that justice is now conceived largely as a distributive problem. "Is Individuals and local communities no longer even conceive of actions which might lead to meeting a need through local skills and resources. Obtaining the resources to expend is the economic issue. How to distribute them equitably to needy consumers is the justice problem.

One root of this justice problem is the emphasis on meeting objective needs. Even a thinker such as Fried, who seeks to solve the distribution problem without basing rights on needs, still voices concern about defining objective needs. ${ }^{\circ}$ Who gives that definition, and what it is, appear to be matters of consequence, for there is great power for those who can specify an objective need and compel resources for their satisfaction by whatever scheme that is "just," whether Rawls', Nozick's, Fried's or some other. It is no surprise to find that expansion of the need concept is a means for professionals to gain more power under the guise of service to mankind. A rethinking of the concept of need may enable the "consumer" to regain control over his own needs, defining them, deciding what meets them, determining if they were met, and thereby exercising his capacity for autonomy and his choice-making skills, making him a self-provider. 
One of the most glaring problems with professional control of needs, defined objectively, is that human needs are reduced to numbers: square feet of housing, minimum daily requirements of calories, vitamins and minerals, certain temperature ranges of BTU's for comfortable living, specified dollar amounts for minimal life-style, completion of $x$ years of education before being educated, and so on. In one sense, some of these measures are accurate. Biologically, we can be fairly objective in saying what mere survival requires. But human needing has far more than a mere material component. Virtually every human need also carries a symbolic, social component. ${ }^{23}$ Falling to recognize this and looking at needs merely as a need for food, clothing, shelter, and the like, often leads to rejection of the professionally provided goods on the part of the ones supposedly being helped. However, recognizing the social component means that needs become excessive. Some examples may make this two-sided concept of needing clearer.

\section{The Breakdown of Conservative Solutions}

Conservative solutions to needs tend to stress the quantitative or objective sense of needs, the bare minimum. Liberal solutions attempt to go beyond such bare minima and allow for what they consider dignity or the quality of life. But neither seems to work. Conservative programs are castigated as miserly, inhuman, crue1, while liberal programs promise bankruptcy and such a degree of professional intervention that meeting the needs eclipses the very liberties and capacities which are the liberal's ends.

Failures are easy to spot. Ghetto housing has provided more square feet of living space, more facilities in terms of plumbing, but destroyed the sense of having a home, leading to widespread abuse and vandalism. A home is not merely a number of square feet. Nor is food just any substance with the proper nutritional mix. Certain African tribes starve before eating fish. Present rack of German shepherd or horse steaks to most Americans and they will not consider it food. Muslims will refuse pork. Calling catsup a vegetable did not go over big in the Eederal school lunch program. Food is something more than its nutritional value. The same may be said of clothing and most other "objective" needs.

\section{Bankruptcy or Paternalism: The Liberal Dilemma}

Looking at needs apart from the social component plays into the hands of those who will define another's 
needs in a primarily quantitative manner. It strips away the basic social mechanism by which individuals, groups, and communities distinguish themselves from one another. How we create a sense of identity and meaningfulness goes directly to the heart of why merely quantitative considerations of needs will be of little interest to the persons bureaucrats and social planners wish to assist. The quantitative approach reduces everyone to a common level while our basic urge to develop an identity leads us to reject such leveling. But going the other way, recognizing the social component, leads to a vast escalation of needs under the rubric of being humanistic, seeing and treating the people according to the way they are. We want to help people retain their identity. How they meet needs contributes to the meaningfulness of this identity. But it may be that what is meaningful is less cost efficient and less effective from a quantitative perspective. The moral obligation to meet needs, now quasi-objective, confronts resource scarcity. Most people, professionals included, would prefer to help those they serve, get more of what meets their unique definition of a need. This beneficent impulse unwittingly adds to professional power. Part of the problem is rooted in the drive to convert activities which meet needs into wage earning so needs can be met by purchases. But this conversion benefits the professional because what has to be bought is usually more or less scarce, requiring his help to obtain.

The professional himself even benefits from the scarcity problem. He becomes an expert on that culture, an advocate getting a bigger piece of the pie for his clients in the zero-sum game that some now see distributive justice becoming.22 Serving needs, helping define them, is almost a description of how to get political power. Bigger programs, more institutions, happier consumers are a desired result. As a sideeffect, those consumers have less need to exercise their autonomy because others are defining and meeting their needs. As already described, the local infrastructure which once had the skills and resources to meet most needs disappears. Instead of seeking resources by which to redevelop such local autonomy, the primary question is how to distribute what someone else produces or to bring in a new industry which will pay high wages. Money then allows the power to consume. Given enough "power." basic needs are said to be met. Any productive activity apart from job performance is never considered. Developing local skills and resources for production of what is neered locally is an almost bizzare notion to social planners or those voicing right claims. Indeed, virtually all the activities of industrial people other than leisure and recreation can be interpreted as adjuncts to wage labor. 
An interesting development in highly industrialized societies is "shadow work." This has been defined by Ivan Illich as unpaid work which is necessary for paid wage labor to take place. ${ }^{23}$ Such work includes housework which makes it possible for the husband to be absent from the household and engage in paid labor. Interestingly, this domestic, unpaid, typically female labor, is not called work nor given the status of being considered in productivity measures. On a different level, the preparation of the public for entry into wage labor and their continued success in the job market is described as meeting a need. We need an education, we need a car to commute to work. We spend time shopping to buy what we need. None of this is typically considered work and is certainly unpaid. The interesting point is that our very needs have changed in a fundamental way, one which meshes with the wage labor requirements of industrial societies. Instead of needing to learn how to produce something to meet a need, we need an education in order to get a job which will provide wages to buy what we need. In this sense we learn to market ourselves. Should we break down or burn out there are various therapies we need, from stress management to counseling. In an industrial society the structure of needing has changed from the skills and materials required for local production to the skills and credentials necessary to earn wages. The enormous amount of unpaid labor required to make wage labor possible is a largely unrecognized version of shadow work. But shadow work goes even further.

At even higher levels of industrialization and consumption exemplified by families with two wage earners, we do find consumers involved in production. In order to save busy consumers time and to cut down on expenses the products are left unfinished. Furniture may need assembly and finishing. Consumers learn to serve themselves and even clean up the tables in fast food outlets. Self-help industries emerge with kits for all manner of items, even houses. Indeed, our choices as consumers have increased and, in a certain sense, our freedom. Whether this add-on shadow work contributes to Braybrooke's desire that alternate life-styles be possible (second order preferences) or whether it merely ties us further into the dependency grids of consumption and wage labor remains to be seen. In any case, professional definition and control over our options by escalation of a need for what they have into a right to have it promises to undermine the liberty to live outside of their prescriptions. 


\section{Rights Eclipse Liberties}

Professionals get together to plan programs for their constituents, ranging from housing, transportation, and education, to health care. Not surprisingly, consumers' needs seem to escalate along with the cries of professionals for the resources to meet them. Since basic needs must be met before anything else, it is less clear when the consumers' "higher human interests" will be exercised. In a somewhat Hegelian sense, the whole tradition of dominating or controlling nature to meet (basic) needs so that higher human interests can be developed seems to have met its contradiction as the means swallow the end and even make it unlikely. The professionalization process, which expresses this larger trend concretely, has become so widespread that the language of needing presupposes it.

\section{Changes in the Language of Needing}

As noted earlier about medicine, the persons deemed in need find themselves labeled as consumers by the providers of their needs who also often define those needs. Needs change slowly from activities expressed by verbs to objects designated by nouns, the products of institutional output. 24 "Need" itself has changed from primarily a verb use to a predominant noun use, as what we need becomes more and more related to consumption and wage labor rather than production skills. Education as a product or service replaces the personal language of "to learn." People now speak of having work instead of doing it. The implication: the replacement of personal activities by professional services or products. As a last example of this implicit thinking of needs in terms of what someone else does, note that the phrase "the health care delivery system" leads one to think health is something like a product one gets, like delivered milk. In a larger context, this phenomenon points to an experiencing of what our needs are and what will meet them primarily in terms of products and services provided by others. In other words, what we need and how it will be satisfied occurs within the horizon of commodities. 2 " Rather obvious problems for autonomy and liberty begin to emerge if the class of objective needs not only expands but comes to be defined and controlled by the professionals who provide the products and services to satisfy the presumed needs.

\section{REGAINING CONTROL OVER OUR NEEDS}

One way to begin enabling people to regain control over their needs is to follow Fried in denying an absolute obligation to satisfy objective needs. What that means would require much more work than a brief 
paper such as this can provide. The second step is to recognize that needs are nearly always experienced with a social component. I do not need calories and nutrients when hungry. I need specific things which are conceived as food: a hamburger, an orange, some milk, and so on. When I need shelter, it is not just square feet I need. .. And the same goes for clothing, transportation, health care, and so on. Part of this recognition of an inevitable symbolic aspect to the human experience of needing is to follow William Leiss in denying the usefulness of the old dichotomies noted earlier in this paper. 26

These need theories were often tied, implicitly and explicitly, to some view of a proper human life or the true human nature. Use of a dichotomous-hierarchical needs theory, in concert with the professionalization of needs, would allow one's own theory of human nature and the proper life to be implemented through the power of the institutions most professionals work within: medicine, law, business, education, and government. of course, a view of proper human functioning and development underlies this critigue. As opposed to an emphasis on providing goods and services, the view of proper human functioning and development presupposed by this critique is one which seeks to enhance the development of the ability to deliberate and reason; to facilitate weighing alternatives on the basis of decision-relevant information; to be able to understand rules and the conduct they require; in short, to develop responsible and autonomous individuals and give them the room, the freedom, to exercise these capabilities. To achieve this we would be better served by returning control of needs to laypersons, helping them become thinking, responsible, autonomous providers, instead of neversatisfied consumers. Now, "control over our needs" does not require production to meet those needs in the sense of self-sufficiency. It refers to a balance between needs met by local and personal methods versus being forced to buy all items needed. A balance between bought and made can enhance liberty. Detailing this balance and how to achieve it is a larger task. Some suggestions are given later in the essay.

What is emphasized here is not patterned end states or the specification of initial starting conditions under which a distribution would be just. Instead, the point is to see the effect of completely losing the ability to meet needs outside of consumption, resulting in the possibility of professional control over our lives. This occurs as professionals seek to make good on rights claims which are based on needs for what is now available only by purchase. Under modern conditions of a market-driven industrial society, starting with need dichotomies and hierarchies leads to professional imposition of a professionally developed view of proper human living. The view that where a basic need 
exists there also exists a primary moral obligation to meet it is the fuel for this process.

\section{Beyond Distribution and Commodities}

A benefit of libertarian theory has been to question the emplasis on distribution and the source of goods. 27 of course, libertarians presuppose the market-driven industrial society that is being questioned here. Rather than follow traditional theorists into a consideration of the justness of end-state principles and patterned distributions, it seems more profitable to question the very presuppositions about the needs these theories are somehow trying to satisfy equitably. Liberty and autonomy should mean more than choices among commodities. Braybrooke says as much when be bemoans the loss of second-order preferences between ways of life and specific vocations. ${ }^{2}$ The use of autonomy in such choices, the having of freedom and opportunities to actually live an unconventional life, speaks of preferences that indicate reflection on what is valuable in one's life. McCloskey, wishing to restrict needs in favor of interests and good human existence, is on the same track. ${ }^{2}$ Illich, in advocating a lifestyle not dominated by wage-labor as a means of meeting needs, certainly has in mind a use of autonomy and freedom other than choice among commodities. Perhaps even Rawls, speaking of life-plans, could be construed in a similar light." I Libertarians however, seem to presuppose the sort of economy which defines man as acquisitive and who finds satisfaction in consumption. The result seems to be incompatible with their own values. ${ }^{32}$

\section{BEYOND NEED DICHOTOMIES}

What then does it mean to deny the usefulness of needs dichotomies and hierarchies? What do we do about meeting needs if we must protect autonomy and liberty from professional erosion by denying that a need implies a right? Certainly all these questions are not answered in a brief paper. Some directions towards the answers are possible though. Denying the usefulness of need dichotomies and hierarchies is in one sense an abandonment of trying to develop a theory about the nature of man and then to make the theory true by implementation of vast programs. The quest abandoned is that of seeking a substantive essence of man, one which lends itself to professionalization. The view advocated is one of man as a process of self-definition, individually and culturally." Further required in this process is a recognition of the power of basic beliefs to influence our behavior and our institutions, a power so strong it sometimes creates the cultural reality it requires to sustain itself. Key to this process 
is a theory of man as capable of autonomy, responsibility, and freedom and a view of the proper $11 \mathrm{fe} a s$ one which maximizes these capabilities. But is not this just as likely to result in professionalization of needs, one may ask? Or will it culminate in a theory of needs which classifies as basic those goods which enhance or make possible autonomy? To be sure, any theory can be perverted; it would be naive to think otherwise. But it does not seem that what is being suggested will result in Rousseau's "forcing people to be free."

The process view of man which picks certain processes such as achieving autonomy as proper would, instead of "forcing freedom," find the end in the means. Encouragement of these capabilities by resource allocations and social programs may indeed encourage people to make choices and take responsibilities for them. But this is not coercion in any usual sense, but rather a reaffirmation of the dignity and worth of individuals. On the other hand, making the choices for another or rendering him so dependent that any remaining choices are specious certainly does not reaffirm these values, even if it may appear from a paternalistic perspective to better meet his "needs."

\section{Fostering Patient Autonomy in Health Care}

A good example of responsibility-enhancing resource allocations is informed consent in medicine. Health care professionals could be trained to encourage participatory decision making. Hospitals could do more work in patient education, including education about patient rights. Reimbursement could shift to encompass time spent in discussion instead of getting paid only upon ordering procedures or tests. Hospitals could operate institutional ethics committees to ensure that rights are respected. Employers and insurors could educate employees and policy holders about their specific diseases and rights. Consumer groups could do the same. All of this would encourage the individual to ask questions, be assertive, and actually get answers in advance of hospitalization to questions which otherwise may not be asked. Such programs would encourage and enable people to make choices and take responsibility for them. This is not coercion, unless one cannot refuse to participate, or cannot abdicate his authority to the professional. There is indeed a theory of human nature and its proper functioning here, but one which rests decision making in the individual.

\section{Rethinking the Origin of Needs}

On a more theoretical level, one way to begin rethinking this issue of human being and needs is to question the idea that we value what we need. Looking 
for what we need in order to decide what is valuable leads us into blind alleys. Reversing the statement, to say that we need what we value, focuses the axiological inquiry properly on values and causes us to really begin thinking at a fundamental philosophical level about world views, absolute presuppositions, the nature of objects, our experience of them, and so forth. While these alleys are not well lit, they at least hold promise of going in a direction that safeguards autonomy and liberty in a fundamental way. When inguiry is directed to values as the foundation, the inquirer is more likely to consider life-plans, the meaning of a good human existence, and second-order preferences than if he begins by considering his needs.

At this point, the distinction between values and needs should be clearly drawn. However, a foray into valuation theory would lead too far astray. The point of phrasing the inquiry in terms of needing what we value is primarily heuristic. For the very language of needing has become so dominated by the thought of professional solutions, providing, consuming, and distributing goods and services, that it does not lead us to think at the same level which a question about values may induce. The purpose of replrasing the question is to lead to a questioning of the current solution to problems about needs.

\section{Decentralization Facilitates Taking Responsibility}

How do we go about meeting needs and yet minimize professionalization of them? My remarks here can be only cursory, but beginnings are possible at several levels. If it is important for people to develop their capacities for autonomy and to exercise it as freedom of choice, then policy makers should encourage resource allocations which stimulate individuals, neighborhoods, and communities to begin conceiving of their needs in terms of the resources available to them and more directly under their control. This emphasis on local and individual autonomy would suggest a process of decentralization, replacing hierarchies with networks. It would seek a balance between use of tools which are under local or individual control and use of tools controlled elsewhere. This move to decentralization, of beginning with values, carries some promise of reducing the power of vast institutions over those they are supposed to serve. The modernized poor, the primary victim of professionalization of their needs, the biggest losers of autonomy and freedom, could be a target group. 34

Encouragement of free enterprise zones, which minimize government interference, should be increased. As a corollary to this, one may conceive a certificationfree zone, such that skills could be developed and practiced without numerous years of unrelated education 
or compulsory union membership, as was intended in the Griggs et al vs. Duke Power Company Supreme Court decision in 1971. 3 In such a zone, the residents might actually begin working with one another in small businesses, light manufacturing, and shops such that they are brought together in the neighborhood workplace. As neighbors, they might then have something in common. Revising welfare programs to encourage defining and meeting individual and local needs at that level would be a part of this strategy. An obvious idea is encouraging development of communal gardens and food co-ops instead of merely dispensing food stamps. Traffic flow in such areas could be redesigned to slow the speed, encouraging the use of walking and bicycles to get back and forth to places that are now accessible without automobiles.36 In other words, neither expensive mass transit nor automobiles are particularly essential if what you need is nearby. Much more could be said about how this changes the experience of poverty. People on the street, working together, defining their needs in terms of their values, might become sufficiently cohesive to bring crime and vandalism under control.

\section{Learning to Live in a Place}

Beyond the encouragement of taking responsibility for oneself and the redevelopment of local skills and resources to meet locally defined needs there is the possibility of rediscovering the place where one is in the traditional sense. Presently most members of industrial society, expecially in urban areas, occupy the places where they live as visitors. Relocation from one urban area to another, or just the expectation of relocation, does little to engender a desire to know anything about an area in terms of its history, geology, biology, or for caring about the long term consequences of our actions on the community or bioregion. We exploit, maximize, and move as if the open frontier was available to make up for our excesses. Visitors come and go, they hold back on making significant commitments, even if their visit may last several years. Thinking in terms of local resources to meet needs focuses our attention on long range issues such as sustainability, carrying capacity, and the like. In short, it turns our attention to where we are and whether it can support us, rather than mere concern with getting more of what we want from somewhere else. The desirable outcome would be a respect for place, a recognition that we are not just visitors but inhabitants. In a sense, this view asks us to behave as if we expect to inhabit our place for all our lives and that our children will do the same. Inhabitants of rural communities still have some sense of what this means, but few policy makers are from rural areas. But even rural people see less and less of what meets their 
needs as being locally produced. Even farmers and ranchers typically buy many of the products they could produce themselves. The time spent in production for use is better spent in production for sale. But, at least the potential for meeting some needs other than by purchase of commodities is possible, an option not available to the urban poor.

\section{Modernized Poverty}

As already alluded to, the scenario just sketched does not advocate community or individual self-sufficiency. Rather, it advocates that communities and individuals begin to reassert control over tools that now dominate them. Institutions meant to help us now control us. Their professional operators often define the clients themselves as deficient in responding to the services or products meant to meet needs imputed to them. Of course, one could respond that the problem of the poor is that their needs are not being met. Who could argue with such a classical definition of poverty? My claim is that the poor not only fail to have their needs met, but they have lost control over defining what their needs are or determining how to meet them. Modernized poverty may be characterized as a poverty in which coping skills other than consumption are lost. Welfare families have few skills and virtually no resources or opportunities by which they could satisfy needs other than by consumption. As a result they lose control over what their needs are and what will satisfy them. Professionals see redistribution of services or goods (often their own) as the solution. The idea of deciding about one's needs and satisfying them through personal productive (as opposed to consumptive) activity is almost unheard of. Imagine a Chamber of Commerce proclaiming that personal activity to meet needs is a solution to unemployment instead of seeking jobs to provide wages.

Again, our language has changed to reveal our reshaped agendas. The italicized "have" in the previous paragraph in the sentence ". : the poor not only fail to have their needs met..." is an example of the change from active doing to passive having. To have needs met implies distribution, with the recipient of need-meeting goods being a passive consuner. What is missing here is the realization that the historical loss of skilis and access to materials by which the poor could meet self-defined needs by their own actions is not a necessary condition of urban life. With this loss of skills and materials comes a new, more radical dependence, a modernized poverty which seems characterized by even less autonomy, responsibility, and freedom than earlier versions of poverty. It seems quite evident that the poverty emerging in "developing" countries is one of dependency, in which the poor lose 
skills and resources which previously enabled them to cope on their own. The vast majority of the poor in the industrial nations have already lost these skills. For them, the only official solution is training, jobs, welfare, income transfers, and the like. One is reminded of certain games in which the object is to run the country in such a way as to at least avoid riots. This of course, involves solving a distribution problem in the game. Again, the program of regaining control over needs is not to advocate a subsistence village economy of self-sufficiency or a Jacksonian rugged individualism, but to suggest that the tools meant to help us are controlling our choices, even our perception of the kinds of choices available. To raise questions about needing what we value is to question a social order and the world view which sustains it.

\section{Synergy Between Types of Tools}

Regaining control over the techne that undermines autonomy and liberty does not mean a carte blanche rejection of techné beyond local or individual control.'7 It means finding, on a local or even individual level, a point of synergy or balance in using tools which are under personal or local control vs. those which are not. The appropriate point of balance, synergy, or control is that which effectively maximizes autonomy and liberty. Defining needs in terms of values, and breaking professional control over their definition, prescription, and evaluation begins this process. The goals are shared by those who advocate night-watchmen states or patterned end principles. This approach finds the end in the means and avoids the problem of unwittingly using a largely unexamined and presupposed concept of human nature through the concept of objective needs and then imposing it by vast social programs which either forces or seduces the clientconsumers into the mold of human nature and the proper life which a dichotomous-hierarchical needs theory implies. There is a concept of human nature and the proper 1 ife here, but it is process-oriented and moves control towards the individual and the local economy. Unlike libertarians, it does not presuppose a marketbased industrial economy in which needs are met primarily by consumption of commodities and obtained by wage labor.

\section{Larger I ssues}

Rethinking needs and the economic infrastructure to meet them is only part of what must be reconsidered. Looking at needs from the perspective of needing what we value pushes the inquiry further. Justice seems to require more than consideration of distribution and must also take participation and production into ac- 
count. Our values concerning the domination of nature and seeing it as a mere storehouse of resources must be reconsidered." In this sense, the political economy being advocated is akin to much of what is currently called bioregionalism, which considers place and its natural systerns as the source of individual wellbeing." People taking local resources and the development of local skills seriously will obviously have to be more interested in what is available and what is possible, both of which require an understanding of the bioregion's systems. To begin looking at needs as based on values, is to begin serious philosophy and a consideration of the implications of how we live.

\section{NOTES}

${ }^{2}$ Herbert Marcuse, One-Dimensional Man (Boston: Bearon Press, 1969), pp. 4-12, considers all but basic biological needs to be historically determined. Needs imposed by others for purposes of repression are false, heteronomous. He holds to this view even if the individual identifies himself with such needs and their satisfaction, even if the conditions of his existence require their satisfaction. Being in this state is false consciousness. A Pandora's box of issues that can only be alluded to here includes determining how we know or verify the objectivity of a need or the objectivity of anything, what it means to have "true" consciousness, the implied idea of a proper human nature, what it is, how it is known, and what personal identity might mean under "false" consciousness, to name the more obvious ones.

${ }^{2}$ Norman Daniels, "Health-Care Needs and Distributive Justice," Philosophy and Public Affairs 10, no. 2 (Spring, 1981): $149-150$.

'Charles Fried, Right and Wrong (Cambridge, Mass.: Harvard University Press, 1978), p. 120, while denying that rights should be based on needs, does indicate that whatever a need is, it must be objective. David Braybrooke, "Let Needs Diminish That Preferences May Prosper," Studies in Moral Philosophy Quarterly Monograph Series, ed. Nicholas Rescher, Monograph no. 1 (Oxford: Basil Blackwell, 1968): 86-107, seeks to reduce the scope of needs because they crowd out resources for preferences. He presupposes the legitimacy of rights claims based on needs and tries to resolve the problem by curtailing what counts as objective needs, since only these carry a rights claim. 
"Abraham Maslow, "A Theory of Human Motivation," Psychological Review 50, no. 4 (July, 1943):- 374-396. His theory, with some adaptations to the business environment, finds widespread use and acceptance in management training and in supervisors courses on motivation. In these courses, little is said about the content of self-actualization or Maslow's prescriptions to transcend materialism.

sBraybrooke, "Let Needs Diminish That Preferences May Prosper," pp. 90-91, 97-102.

'Ibid. P. 93; T. M. Scanlon, "Preference and Urgency." Journal of Philosophy 72, no. 19 (November 6 , 1975): $6 \overline{55-669}$, esp. pp. 656-659, points out the importance of having objective, not subjective criteria of well-being for it to have any basis for moral claims.

'Braybrooke, pp. 98-100. Social status needs are what we must have to maintain our sense of worth. Social change needs arise from technological changes which result in needs for automobiles, electricity, and so on.

"See Caroline Whitbeck, "A Theory of Health," in Concepts of Health and Disease, eds. Arthur L. Caplan, H. Tristram Engelhardt, Jr., and James J. McCartney (Reading, Mass.: Addison-Wesley, 1981), pp. 614-615 and H. Tristram Engelhardt, Jr.. "Human Well-Being and Medicine: Some Basic Value Judgements in the Biomedical Sciences," in Biomedical Ethics eds. Thomas A. Mappes and Jane S. Zembaty (New York: McGraw Hill. 1981). pp. 213-222.

'H. J. McCloskey, "Human Needs, Rights, and Political Values," American Philosophical Quarterly 13, no. 1 (January, 1976): 1-11. Daniels, "Health-Care Needs," presents his own hierarchy of needs, but it is based on Braybrooke and McCloskey, and in the space available will not be considered.

20 Ibid. , p. 5-7.

1'Marcuse, One-Dimensional Man, pp. 4-12. This critique of normalcy as a sufficient criterion is widespread. Erich Eromm, The Sane Society. (Greenwich, Conn: Fawcett Publishers, 1955) picks it up along with the whole host of counter-culture and alternative lifestyle writers dating to the $1960^{\circ} \mathrm{s}$.

12Daniels, "Health-Care Needs," pp. 168-174, uses McCloskey's theory, but leaves out the key idea of relating needs to human good. Daniels also finds that wherever there is a need, it should be satisfied. 
Given the escalation of health care needs, he gives a narrow definition of health but still produces a very comprehensive list of needs, implying vast institutional programs to meet them.

13 Mccloskey could be said to have merely done the same. However, the capacities and capabilities he noted were part of a good or essential human nature. Needs were true when related to good development of this nature. But what would count as that good development was not clear.

"Henry Shue, Basic Rights: Subsistence, Affluence, and U.S. Foreign Policy (Princeton, NJ: Princeton University press, 1980) takes this view, along with a number of writers about health care.

1s John Rawls, A Theory of Justice (Cambridge, MA: Balnap Press, 1971E).

"Karl Popper, The Open Society and Its Enemies, fourth edition, (New York: Harper Torch Books, 1962), shows how the political views of Plato, Hegel, and Marx readily assist enemies of democracy owing to the emphasis on centralized control.

'Description of the professionalization process draws on Jon Mcknight, "Professionalized Service and Disabling Help," in Disabling Professions (London: Marion Boyars, 1977), pp. 69-72. Ivan Illich, Medical Nemesis (New York: Random House, 1976), pp. 1 $\overline{22-220,}$ describes the general process of means preventing the achievement of the ends for which they were established as paradoxical counterproductivity.

"Illich, Medical Nemesis.

"Libertarians make this point. See Robert Nozick, Anarchy, state, and Utopia, (New York: Basic Books, 1974).

${ }^{\circ}$ Eried, Right and Wrong, pp. 117-131.

2'The discussion of needs as having both a material and a symbolic component is indebted to willian Leiss, Limits to Satisfaction: An Essay on the Problem of Needs and Commodities (Toronto: University of Toronto Press, 1976).

${ }^{22}$ Lester Thurow, The Zero-Sum Society, (New York: Penguin, 1981).

${ }^{2} I l l i c h$, Shadow Work, (Salem, NH: Marion Boyars, 1981), pp. 99-116, esp. pp. 99-101. 
"Ivan Illich, Tools for Conviviality (New York: Harper and Row, 1973), pp. 96-99 and Toward a History of Needs (New York: Bantam, 1977), pp. 33-34.

${ }^{28}$ Leiss, Limits to Satisfaction, pp. 71-92, provides an excelient analysis of commodities from which this analysis is drawn. After a review of Marx's views, Leiss concludes--rightly I think--that commodities become a bundle of characteristics with no more substance than a Humean self.

${ }^{26}$ Leiss, Limits to Satisfaction, pp. 49-71.

${ }^{27}$ Nozick, Anarchy, State, and Utopia, pp. 149-150, see note 32 .

2"Braybrooke, "Let Needs Diminish," pp. 100-102.

29 McCloskey, "Human Needs, Rights, and Political Values," pp. 7-9.

${ }^{30}$ See note 23 .

"John Rawls, A Theory of Justice (Cambridge, MA: Belknap Press, 1971). This claim is based on Rawls' definition of primary goods, that life plans themselves are good when they accord with rational desire, leading eventually to self-respect being the most primary good. Rawls obviously would seek to maximize autonomy and opportunities for choice-making, even if there is no special goodness to the deciding act (p. 418). His other primary goods, likewise, are not mere commodities.

${ }^{32}$ My own position differs substantially from libertarians for several reasons. Peter Singer, "Rights and The Market," in Justice and Economic Distributions, eds. Johns Arthur and William H. Shaw (Englewood Cliffs, New Jersey: Prentice-Hall, 1978), pp. 207-221, esp., 212-216, discusses some of those reasons, such as the change of experience when something is conceived as exchangeable, the conversion of rights into commodities, and the resulting commercialization of life. My own criticisms would go even further and question the very reliance on an industrial system and its markets leading inexorably, it seems, to such large organizations that a night-watchman state would be unable to check the intrusions on liberty and autonomy which 1ibertarians and myself so value.

'The classic text by Peter $L$. Berger and Thomas Luckman, The Social Construction of Reality, (Garden City, New York: Doubleday, 1967) has been very important in developing this position. 
"Eor a discussion of the modernized poor, see I11ich, Toward a History of Needs, pp. 10-13.

"Ibid. . p. 99.

3 "Even the popular press recognizes this problem. See Wolf Von Eckart, "Trying to Tame the Automobile," Time, 12 October 1981, pp. 87-89. See also Illich, Toward a History of Needs, pp. 141-143, 151-153 for a more theoretical discussion, and David G. Wilson, "Getting in Gear: Human-Powered Transportation," Technology Review 82, no. 1 (October, 1979): 42-54 for a discussion of the practicality and impracticality of human-powered transportation.

"The phrase "techné" is used to point to some of the more fundamental metaplysical issues concerning technology and science which Martin Heidegger. The Question Concerning Technology trans. William Lovitt (New York: Harper and Row, 1977) points towards.

"For two examples of this literature, see Edward G. Ballard, Man and Technology (Pittsburg: Duguesne University Press, 1978) who develops a theory of self, while evaluating a society driven by the values of technology, and Morris Berman, The Reenchantment of the World (Ithaca, New York: Cornell University Press, 1981) who describes the historical development of the metaphysics of industrial-technological-capitalistic society and some ideas at corrective presuppositions.

"See Jim Dodge, "Living by Life: Some Bioregional Theory and Practice," Co-Evolution Quarterly 32, (Winter, 1981): 6-12. The whole issue is devoted to bioregionalism. 